\title{
SHORT COMMUNICATIONS
}

\section{Solution-Grown Single Crystal of Polyacrylonitrile Polymerized by $\gamma$-Ray Irradiation on Urea-Acrylonitrile Canal Complex: Preparation and Preliminary Structure Analysis}

\author{
Hitoshi YAMAZAKI, Shuji KAJITA, and Kenji KAMIDE* \\ Fundamental Research Laboratory of Fibers and Fiber-Forming Polymers, \\ Asahi Chemical Industry Co., Ltd., 11-7 Hacchonawate, \\ Takatsuki, Osaka 569, Japan
}

(Received March 27, 1987)

\begin{abstract}
KEY WORDS Polyacrylonitrile / Stereoregularity / Single Crystal Solution Grown Crystal / Crystal System / Crystal Lattice Constant / Isotactic Polymer /
\end{abstract}

Up to now, many attempts to analyze comprehensively the crystal structure of polyacrylonitrile (PAN) ${ }^{1-9}$ have unfortunately ended unsuccessfully, due to lack in off-equatorial sharp reflections in X-ray diffraction photographs of PAN fibers and an insufficient number of sharp reflections of multi-layered solution grown crystals in the electron diffraction patterns. The experimental difficulties encountered in the above studies are (1) preparation of fibers with highly-oriented and welldeveloped crystals and (2) preparation of solution-grown single crystals.

Table I summarizes the polymerization method of the polymer sample employed and the crystal form and its lattice constants proposed so far. For all polymer samples in literature, ${ }^{1-9}$ stereoregularity was not evaluated. Considering that these polymer were, without exception, synthesized by free-radical or anionic polymerization and also considering the recent advance in NMR characterization of PAN, these polymers could be classified as atactic PAN (i.e., completely random in stereoregularity, shortly random polymers). Therefore, it is concluded that the fragmental crystallographic knowledge in literature was obtained only from atactic, or at most less stereoregular PAN samples, and this fact could explain why unsatisfactory crystallographic data have accumulated.

$\mathrm{Kast}^{2}$ was probably the first to study the Xray diffraction of atactic $\mathrm{PAN}$ fibers, prepared by radical polymerization, concluding that the PAN crystals are hexagonal lattices. Two years later, Natta et $a l .^{3}$ reached to a similar conclusion (hexagonal form) for atactic PAN fibers, prepared by anionic polymerization. Urbanczyk $^{4}$ reported the PAN crystal form to be pseudo hexagonal. Stefani et al. ${ }^{5}$ proposed an orthorhombic cell (space group $\mathrm{Cmc}$ ) for PAN, although the density calculated from the proposed crystal structure $\left(1.13 \mathrm{~g} \mathrm{~cm}^{-3}\right)$ was significantly lower than the experimental value $\left(1.20 \mathrm{~g} \mathrm{~cm}^{-3}\right)$. The validity of the orthorhombic form was hence repeatedly confirmed for PAN crystals by Mencik ${ }^{6}$ and Colvin and Storr $^{7}$, who showed the calculated density to agree with the experimental density. Holland and his coworkers ${ }^{8}$ insisted on the orthorhombic cell by analyzing the electron diffraction photographs of crystal mats with

\footnotetext{
* To whom correspondence should be addressed.
} 
Table I. Crystal system and lattice constants of polyacrylonitrile in the literature

\begin{tabular}{|c|c|c|c|c|c|c|c|c|c|c|c|}
\hline \multirow{3}{*}{ Author(s) } & & \multirow{3}{*}{$\begin{array}{l}\text { Crystal } \\
\text { system }\end{array}$} & \multirow{3}{*}{$\begin{array}{l}\text { Point } \\
\text { group }\end{array}$} & \multirow{3}{*}{$\begin{array}{l}\text { Space } \\
\text { group }\end{array}$} & \multicolumn{3}{|c|}{ Lattice constant } & \multirow{3}{*}{$\begin{array}{l}\text { Polymn. } \\
\text { method }\end{array}$} & \multirow{3}{*}{ Sample } & \multirow{3}{*}{ Method } & \multirow{3}{*}{ Ref } \\
\hline & & & & & & $\AA$ & & & & & \\
\hline & & & & & $a$ & $b$ & $c$ & & & & \\
\hline Kast & (1957) & $\operatorname{Hexa}^{a}$ & - & - & 6.17 & 6.17 & 5.1 & Radical & $F^{d}$ & $\mathrm{XD}^{\mathrm{g}}$ & 2 \\
\hline Natta et al. & (1958) & Hexa & 一 & - & 5.99 & 5.99 & - & Anionic & $\mathrm{F}$ & XD & 3 \\
\hline Stefani et al. & (1960) & Ortho $^{b}$ & $\mathrm{~mm} 2$ & $\mathrm{Cmc} 2$ & 10.22 & 6.10 & 5.10 & Radical & $\mathrm{F}$ & $\mathrm{XD}$ & 5 \\
\hline Mencik & (1960) & Ortho & - & - & 18.1 & 6.12 & 5.00 & Radical & $\mathrm{F}$ & $\mathrm{XD}$ & 6 \\
\hline Holland et al. & (1962) & Ortho & - & - & 10.55 & 5.82 & - & Radical & $\mathrm{CM}^{\mathrm{e}}$ & $E D^{h}$ & 8 \\
\hline Urbanczyk & (1962) & PHexa ${ }^{c}$ & - & - & 6.1 & 6.11 & $(5.1)$ & Radical & $\mathrm{F}$ & $\mathrm{XD}$ & 4 \\
\hline Klement and Geil & (1968) & Ortho & - & - & 21.18 & 11.60 & (5.1) & Radical & $\mathrm{CM}$ & $\mathrm{XD}, \mathrm{ED}$ & 9 \\
\hline Colvin and Storr & (1974) & Ortho & - & - & 21.48 & 11.55 & 7.096 & Radical & $\mathrm{F}$ & $\mathrm{XD}$ & 7 \\
\hline This work & (1987) & Ortho & $(\mathrm{mm} 2)$ & $\left(\mathrm{Pna}_{1}\right)$ & 10.7 & 12.1 & - & $\begin{array}{l}\text { Urea canal } \\
(\gamma \text {-ray })\end{array}$ & $S C^{\mathrm{f}}$ & ED & - \\
\hline
\end{tabular}

a Hexa, hexagonal. b Ortho, orthorhombic. ' PHexa, pseudo hexagonal. ' $\mathrm{d}$, fiber.

e CM, crystal mat. ${ }^{\mathrm{f}} \mathrm{SC}$, single crystal. ${ }^{\mathrm{g}} \mathrm{XD}, \mathrm{X}$-ray diffraction. ${ }^{\mathrm{h}} \mathrm{ED}$, electron diffraction.

about $100 \AA$ thickness (they claimed platelet for the mats), grown from $0.1-1.0 \%$ PAN solution in propylenecarbonate at $90-100^{\circ} \mathrm{C}$. Similarly, Klement and $\mathrm{Geil}^{4}$ performed a study on solution grown radical PAN mat from a propylenecarbonate solution, concluding the orthorhombic cell. The lattice constants $a$ and $b$ by Klement and Geil are in good agreement with those by Colvin and Storr, but are just twice those by Holland et al. (see Table I). Solution grown crystal mats, reported by Holland et al. ${ }^{8}$ and Klement and $\mathrm{Geil}^{9}$, were of ellipse shape and no distinct growing plane was observed. Therefore, these mats, in a strict sense, cannot be regarded as single crystals. Moreover, the electron micrographic investigation showed that these mats were very occasionally heavily multilayered. As the results, their reflection spots were not sharp, but very diffuse (see for example, Figure 11 of ref 9 ).

In this article, an attempt was made to prepare single crystals from dilute solution of highly isotactic PAN, polymerized by $\gamma$-ray irradiation, and to determine the crystallographic features such as the crystal form, its growth plane and the lattice constants.

\section{EXPERIMENTAL}

\section{Preparation and Characterization of Polymer Samples}

Recently, Yamazaki ${ }^{10}$ succeeded in establishing a method for controlling the molecular weight of highly isotactic PAN in the polymerization process of $\gamma$-ray irradiation on acrylonitrile-urea canal complex $(\gamma-\mathrm{PAN})$ with the addition of $n$-alkyl mercaptan. We used a $\gamma$-PAN sample, synthesized according to the procedure by Yamazaki. ${ }^{10}$

The stereoregularity of the sample was evaluated from the ${ }^{13} \mathrm{C}$ NMR spectrum in DMSO $-d_{6}$ to be $70 \%$ isotactic triad, $22 \%$ heterotactic triad and $8 \%$ syndiotactic triad. ${ }^{11,12}$ The viscosity-average molecular weight $\bar{M}_{v}$, determined from the limiting viscosity number $[\eta]$ in DMSO at $25^{\circ} \mathrm{C}$ using the Mark-Howink-Sakurada equation proposed by Kamide et al., ${ }^{13}$ was $1.49 \times 10^{5}$.

\section{Preparation of Single Crystals}

The $\gamma$-PAN sample was dissolved in ethylenecarbonate at $155 \pm 5^{\circ} \mathrm{C}$ to give a $0.5 \mathrm{wt} \%$ solution. The solution settled in glycerin bath maintained at $95 \pm 0.2^{\circ} \mathrm{C}$ for 7 days to com- 
plete isothermal crystallization.

\section{Electron Diffraction and Electron Micrographs}

A small amount of the solution, isothermally well crystallized, was dropped onto the grid of an electron micrograph (EM), washed with ethylenecarbonate and methanol several times. The specimen was shadowed with platinum at an angle of $30^{\circ} \mathrm{C}$ toward the grid surface in a vacuum evaporator HUS-4 type manufactured by Hitachi (Tokyo, Japan) at $10^{-6} \mathrm{mmHg}$. The specimen, prepared thus, was transferred to an EM JEM-1200EX, manufactured by JEOL (Tokyo) and the morphology of the specimen was observed under the following conditions: bright field image, magnification $\times 5000$. The selected area electron diffraction was also obtained for the specimen. In order to minimize possible damage to the crystals due to electron irradiation, the photographs were taken at an electron dose as small as possible.

\section{RESULTS AND DISCUSSION}

Figure 1 shows a typical micrograph of $\gamma$ PAN crystals grown from the solution in ethylenecarbonate at $95^{\circ} \mathrm{C}$ for 7 days. Although the crystal mats reported in literature for atactic PAN were heavily multilayered or agglomerated, Figure 1 indicates that highly isotactic PAN gives a single lamella if the polymer is isothermally crystallized under adequate conditions. Holland et al. ${ }^{8}$ and Klement and $\mathrm{Geil}^{9}$ obtained elongated ellipse crystal mats for atactic PAN and the latter noted that it was no longer possible to detect the main original lamella. A solution-grown $\gamma$ PAN crystal is a lozenge, with well-defined sides, closely associated with crystal growth faces. Judging from the electron diffraction patterns (see Figure 2), the directions of the $a$ and $b$-axes are determined as indicated by arrows and one of four sides is assigned to the (110) plane. The solution-grown crystals each has a side of about $3 \mu \mathrm{m}$ in length and ap-

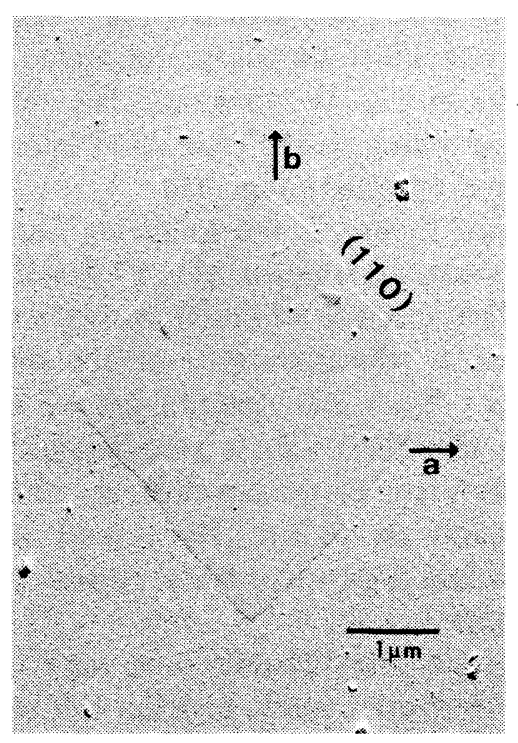

Figure 1. Electron micrograph of a single $\gamma$-PAN crystal, grown for 7 days from a $0.5 \mathrm{wt} \%$ ethylenecarbonate solution at $95^{\circ} \mathrm{C}$.

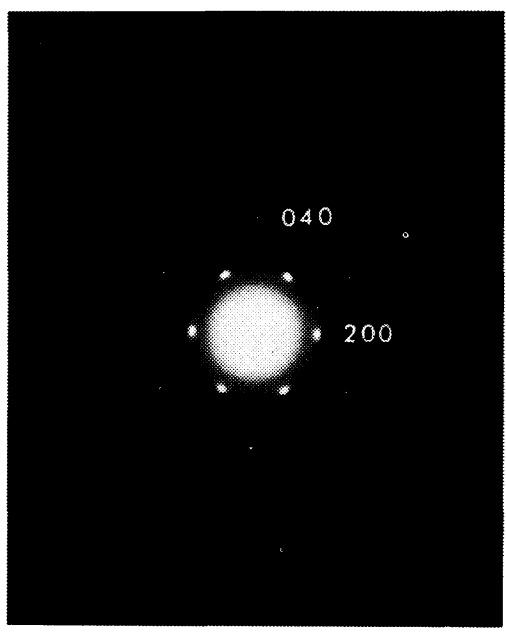

Figure 2. Electron diffraction patterns of a single $\gamma$ PAN crystal, grown for 7 days from a $0.5 \mathrm{wt} \%$ ethylenecarbonate solution at $95^{\circ} \mathrm{C}$.

proximately $100 \AA$ in thickness. The solutiongrown crystals of $\gamma$-PAN have a shape similar to that of polyethylene single crystals (but not hollow pyramids) and these $\gamma$-PAN crystals can be regarded as single planar lamella crystals.

Figure 2 shows an electron diffraction pat- 
tern of a solution-grown $\gamma$-PAN crystal. All reflection spots are sharp and higher ordered reflections can be observed. The reflections, corresponding to the crystallographic planes, 200 and 040, are designated.

From Figure 2, the following lattice constants were determined: $a=10.7 \AA$ and $b=12.1$

$\AA$. The electron diffraction pattern corresponds to the symmetry of the diffraction group $^{14} 2 \mathrm{~mm}$ and accordingly, we can conclude that the $c$-axis is perpendicular to the surface plane of the lamellae, on which PAN molecules are folded. The crystal system of the solution-grown $\gamma$-PAN crystal is orthorhombic.

The 200 and 120 reflections have relatively large intensities and in general, $h k 0$ reflections are observable under any condition (indicating that the crystal is not C-centered) and h00 and $0 k 0$ reflections are observed only in the case of $h=2 n$ and $k=2 n$, respectively. For an orthorhombic system, the space groups satisfying these rules are evidently limited to $P 2_{1} 2_{1} 2_{1}$, Pba2, Pna2, Pnn2, Pnnm, and Pnam. Unfortunately, the information about extination rules in relation to the $c$-axis direction cannot be obtained from the electron diffraction pattern of lamella crystals and hence, judging from the X-ray diffraction patterns of Colvin and Storr (Figure 2 of ref 7) 001 reflections should be possible only in the case of $l=2 n$. The space groups among the above six types of symmetry, satisfying this additional condition, are $\mathrm{P} 22_{1} 2_{1} 2_{1}, \mathrm{Pna} 2_{1}, \mathrm{Pnn} 2$, Pnnm, and Pnam. If we assume a two-fold screw axis in the $c$-direction, the probable space groups are $\mathrm{P} 2_{1} 2_{1} 2_{1}$, Pna $2_{1}$, and Pnam (full symbol, P 2//n 2/a $2 / \mathrm{m}$ ). These space groups do not coincide with $\mathrm{Cmc} 2$ proposed by Stefani et $a .^{5}$ More detailed work on solution grown PAN crystals is in progress.

\section{REFERENCES}

1. C. R. Bohn, J. R. Schaefgen, and W. O. Statton, J. Polym. Sci., 55, 531 (1961).

2. W. Kast, in "londolt-Börnstein Tabelen," Vol. 4, 6th ed, Part 3, Springer-Verlag, Berlin, 1957.

3. G. Natta and G. Dall'Asta, Italian Patent, 570,434 (1959); G. Natta, G. Mazzanti, and P. Corradini, Atti. Accad. Nazl. Lincei. Rend. Classe Sci. Fis. Mat. Nat., 25, 3 (1958).

4. G. W. Urbunczyk, Zeszyty Nauk, Politech. Lodz, Wlokiennictwo, 9, 79 (1962); Chem. Abstr., 61, 5836B (1964).

5. R. Stefani, M. Chevereton, M. Garnier, and C. Eyrand, Compt. Rend., 251, 2174 (1960).

6. Z. Mencik, Vysokomolekul. Soedin, Ser. A, 2, 1635 (1960).

7. B. G. Colvin and P. Storr, Eur. Polym. J., 10, 337 (1974).

8. V. H. Holland, S. B. Mitchell, W. L. Hunter, and P. H. Lindenmeyer, J. Polym. Sci., 62, 145 (1962).

9. J. J. Klement and P. H. Geil, J. Polym. Sci., A-2, 6, 1381 (1968).

10. H. Yamazaki, unpublished results.

11. K. Kamide, H. Yamazaki, K. Okajima, and K. Hikichi, Polym. J., 17, 1233 (1985).

12. K. Kamide, H. Yamazaki, K. Okajima, and K. Hikichi, Polym. J., 17, 1291 (1985).

13. K. Kamide, H. Yamazaki, and Y. Miyazaki, Polym. J., 18, 819 (1986).

14. see, for example, B. F. Buxton, J. A. Eades, J. W. Steeds, and G. M. Rackham, Phil. Trans. R. Soc. London, Ser. A, 281, 171 (1976). 